Correspondence

Ewa Augustynowicz

eaugustynowicz@pzh.gov.pl

Received 13 June 2003

Accepted 11 August 2003

\section{Comparison of usefulness of randomly amplified polymorphic DNA and amplified-fragment length polymorphism techniques in epidemiological studies on nasopharyngeal carriage of non-typable Haemophilus influenzae}

\author{
Ewa Augustynowicz, ${ }^{1}$ Anna Gzyl, ${ }^{1}$ Leszek Szenborn, ${ }^{2}$ Dorota Banys, ${ }^{2}$ \\ Grzegorz Gniadek ${ }^{1}$ and Janusz Ślusarczyk ${ }^{1}$ \\ ${ }^{1}$ Department of Sera and Vaccine Evaluation, National Institute of Hygiene, Chocimska 24 St, 00-791 \\ Warsaw, Poland \\ ${ }^{2}$ Department of Infectious Diseases of Children, Medical University, Wroclaw, Poland
}

\begin{abstract}
Randomly amplified polymorphic DNA (RAPD) and automated amplified-fragment length polymorphism (AFLP) techniques with fluorescently labelled primers were used to type nonserotypable Haemophilus influenzae (NTHI) isolates. Eighty-seven isolates from healthy children attending day-care centres or living at orphanages in southern Poland were investigated. Through comparison of the AFLP data with RAPD analysis, it has been concluded that the discriminatory power of AFLP for NTHI typing is higher than RAPD. Generally, the NTHI isolates analysed were highly heterogeneous, as detected with a Hindlll/Taql AFLP genotyping scheme on intra/inter similarity levels of 94 and $96 \%$ using Pearson's correlation coefficient. The range of similarity values found for isolates from children permanently residing at a particular day-care centre was much wider than that for isolates from orphanages. AFLP can efficiently access NTHI strain diversity and can monitor their turn-over for comparative typing in local and inter-local epidemiological investigations.
\end{abstract}

\section{INTRODUCTION}

Non-serotypable Haemophilus influenzae (NTHI) strains commonly colonize the upper respiratory tracts of children under $4-5$ years of age and are implicated in otitis media, sinusitis, bronchitis and conjunctivitis manifestations (Cerquetti et al., 2000; Peltola, 2000; Urwin et al., 1996). The carriage of NTHI and other capsular types (a and c-f) strains may increase in frequency and its relative clinical importance might grow as a consequence of the reduction of $H$. influenzae type $\mathrm{b}(\mathrm{Hib})$ carriage and its infections as a result of vaccination against Hib (Hargreaves et al., 1996; Leaves \& Jordens, 1996; Omikunle et al., 2002; Urwin et al., 1996). Additionally, a decrease in Hib carriage has been suspected to increase infections with other species such as Streptococcus pneumoniae or Haemophilus parainfluenzae (Peltola, 2000). In Finland, implementation of Hib vaccination has been positively correlated with an increase in paediatric pneumococcal disease (Leaves \& Jordens, 1996). Thus, selective vaccination pressure is capable of inducing

Abbreviations: AFLP, amplified-fragment length polymorphism; DCC, daycare centre; Hib, $H$. influenzae type b; NTHI, non-typable $H$. influenzae; RAPD, randomly amplified polymorphic DNA. changes in serotype distribution in a given population and, moreover, NTHI might replace Hib strains as the predominant cause of $H$. influenzae disease. Monitoring of $H$. influenzae carriage is a potent method of evaluating the importance of serotypes after vaccine implementation (Pettigrew et al., 2002; Smith-Vaughan et al., 1998).

Encapsulated $H$. influenzae strains are known to be successfully subclassified by serotyping, biochemical testing, outermembrane protein typing, lipopolysaccharide analysis, multilocus enzyme electrophoresis (MLEE) and multilocus sequence typing (Fuste et al., 1996; Gazagne et al., 1998; Meats et al., 2003; Moor et al., 1999; Spinola et al., 1986; St Geme et al., 1994; van Belkum et al., 1994). All published data recognize encapsulated $H$. influenzae population structure as clonal (Moor et al., 1999; Musser et al., 1988; Omikunle et al., 2002). Furthermore, most invasive Hib disease worldwide has been found to be caused by a limited number of bacterial clones (Saito et al., 1999; Smith-Vaughan et al., 1998). Compared with encapsulated strains, non-encapsulated $H$. influenzae are less well characterized and are thought to be more diverse (Fuste et al., 1996). Most studies directed towards recognizing links between closely related but not identical NTHI strains have been conducted by application 
of MLEE or randomly amplified polymorphic DNA (RAPD) techniques (Fuste et al., 1996; Jordens et al., 1993; van Alphen et al., 1997).

This study presents the first report on amplified-fragment length polymorphism (AFLP) differentiation performed on a representative number of NTHI isolates, coupled with estimation of their genetic relationship. The presence of the cap locus among pharyngeal isolates of NTHI was also examined. Some aspects of the effect of bacterial persistence in hosts who differ in levels of close contacts and on the genetic diversity of the $H$. influenzae population are discussed.

\section{METHODS}

Description of the group. In total, $87 \mathrm{H}$. influenzae isolates obtained from healthy children who attended day-care centres (DCC) or orphanages and their teachers. DCCs refer to childcare institutions in which children are resident during the time that their parents are at work, generally between 7 a.m. and 4 p.m. Orphanages refer to special care institutions in which children waiting for adoption or without parental supervision reside permanently. From January to May 2002, public health nurses from six DCCs and three orphanages in different regions of the western part of Poland collected nasopharyngeal swabs from healthy 3- to 5-year-old children. In collecting samples, nurses swept a cotton-tipped applicator over the nasopharynx and then immediately placed the swab in transport medium (Medlab). The material was processed on the same day in a microbiological laboratory. All individuals tested were not vaccinated against Hib and none of the children was acutely ill. The Ethical Committee of the Medical Academy in Wroclaw approved the research protocol.

Bacterial isolates and culture media. All $H$. influenzae isolates were grown on chocolate agar plates at $37^{\circ} \mathrm{C}$ in $5 \% \mathrm{CO}_{2}$ or in brain heart

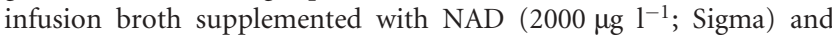
haemin $\left(2000 \mu \mathrm{gl}^{-1}\right.$; Sigma). Isolates were identified as $H$. influenzae on the basis of Gram reaction, cell morphology, lack of $\beta$-haemolysis and $\mathrm{NAD}$ and haemin requirements. Isolates were assigned to biotypes on the basis of standard tests for indole, urease and ornithine decarboxylase production. The lack of agglutination with antiserum (Difco) determined the non-typable character of the isolates. Isolates were kept as frozen stocks at $-70{ }^{\circ} \mathrm{C}$ in broth containing $15 \%$ glycerol, usually after fewer than five passages from the primary culture plate.

In the study, $H$. influenzae ATCC 49766, $H$. influenzae type b ATCC 10211 and 24 Hib strains (isolated from cerebrospinal fluid from children with meningitis) were used as controls.

Isolation of total DNA. Bacteria were grown on brain heart infusion broth supplemented with $\mathrm{NAD}$ and haemin to an $\mathrm{OD}_{650}$ of the culture suspension of $0 \cdot 25$.

DNA for AFLP analysis was prepared according to the method of Bolduc et al. (2000). Two millilitres of overnight culture of $H$. influenzae was centrifuged at $5000 \mathrm{~g}$ for $10 \mathrm{~min}$ at $4{ }^{\circ} \mathrm{C}$, resuspended in $3 \mathrm{ml} 50 \mathrm{mM}$ Tris/HCl, $20 \mathrm{mM}$ EDTA (pH 8.0) and recentrifuged. The cell pellet was resuspended in $4 \mathrm{ml} 50 \mathrm{mM}$ Tris/HCl, 2 mM EDTA ( $\mathrm{pH}$ 8.0) containing $1 \mathrm{mg}$ lysozyme and incubated for $30 \mathrm{~min}$ at $4{ }^{\circ} \mathrm{C}$. Addition of $1 \mathrm{mg}$ proteinase $\mathrm{K}$ and $0.3 \mathrm{ml} 10 \% \mathrm{SDS}$ was followed by incubation of the lysate with agitation for $4 \mathrm{~h}$ at $56{ }^{\circ} \mathrm{C}$. Next, $1 \mathrm{ml} 10 \%$ lauroylsarcosine was added. Chromosomal DNA was purified with phenol/chloroform/ isoamyl alcohol $(25: 24: 1)$ and precipitated with absolute ethanol overnight at $-20^{\circ} \mathrm{C}$. DNA was harvested by centrifugation at $12000 \mathrm{~g}$ for $20 \mathrm{~min}$, washed with $70 \%$ ethanol and resuspended in $100 \mu \mathrm{TE}$ buffer with DNase-free RNase $\left(0.25 \mathrm{mg} \mathrm{ml}^{-1}\right)$ for $1.5 \mathrm{~h}$ at $37^{\circ} \mathrm{C}$. DNA for RAPD typing was extracted by use of the QIAamp Mini kit (Qiagen).

The concentration of the DNA was measured by electrophoresis of samples on $1 \%$ agarose gel with a diluted preparation of $\lambda$ phage DNA of known concentration.

Confirmation of serotype and detection of capsule genes by PCR. All NTHI and Hib isolates were subjected to PCR as described by Falla et al. (1994), using primers directed to the bexA region and the type b-specific region. Primers H1 (5'-CGTTTGTATGATGTTGATCCA GAC-3'), H2 (5'-TGTCCATGTCTTCAAAATGATG- $\left.3^{\prime}\right)$, b1 (5'GCGAAAGTGAACTCTTATCTCTC-3') and b2 (5'-GCTTACGCT TCTATCTCGGTGAA- $3^{\prime}$ ) were used. A product of $343 \mathrm{bp}$ obtained from amplification with primers $\mathrm{H} 1$ and $\mathrm{H} 2$ confirmed capsulation, and generation of a 480-bp product with primers b1 and b2 indicated specific capsulation.

Typing by the RAPD method. RAPD differentiation was performed by using Ready-to-Go RAPD analysis beads (Amersham Pharmacia Biotech). Primers I (5'-GGTGCGGGAA-3'), II (5'-GTTTCGCTCC$\left.3^{\prime}\right)$, III (5'-GTAGACCCGT-3'), IV (5'-AAGAGCCCGT-3'), V (5' AACGCGCAAC-3') and VI (5'-CCCGTCAGCA- $\left.3^{\prime}\right)$ were used. Fortyfive cycles of denaturation at $94{ }^{\circ} \mathrm{C}$ for $1 \mathrm{~min}$, annealing at $36{ }^{\circ} \mathrm{C}$ for $1 \mathrm{~min}$ and extension at $72{ }^{\circ} \mathrm{C}$ for 1 min were applied in a Biometra thermal cycler. Aliquots of amplified PCR products were electrophoresed in a $1.5 \%$ agarose gel stained with ethidium bromide. Electrophoresis was carried out in TAE buffer $(40 \mathrm{mM}$ Tris/acetate, $1 \mathrm{mM}$ EDTA). Gels were photographed with the Gel Doc 1000 Gel Documentation system (Bio-Rad). Stored patterns were analysed with the Windows version of GelCompar software version 3.10 (Applied Maths) after conversion of the data into the TIF format. Electrophoresis gels were normalized according to external standards contained in each fifth lane (1 kb ladder, Gibco).

Typing by the AFLP method. Firstly, five DNAs isolated from representatives of the NTHI strain collection were used in screening analysis to evaluate the potential to obtain distinctive AFLP patterns. Seven different AFLP sets were used, HindIII/TaqI, two different ApaI/ TaqI sets, HindIII, MfeI/BglII, PstI/TaqI and EcoRI/MseI, based on different enzyme restriction/specific adaptor ligation and primerspecific amplification with/without selective bases complementary to nucleotides flanking the restriction sites. They were previously found to work with species other than $H$. influenzae (Grady et al., 1999; Huys et al., 1996; Kokotovic et al., 1999; McLauchlin et al., 2000; van Eldere et al., 1999; Vos \& Kuiper, 1998). Characteristics of AFLP sets are presented in Table 1. Sequences of adaptors/primers and thermal conditions were applied as described previously but different conditions of restriction, ligation and amplification reactions were applied. Briefly, in all tested AFLP sets, $200 \mathrm{ng} \mathrm{H}$. influenzae DNA was digested with the following restriction enzymes: HindIII (BioLabs)/TaqI (Gibco-BRL), ApaI (BioLabs)/TaqI, HindIII, MfeI (BioLabs)/BglII (BioLabs), PstI (Eurogentec)/TaqI and EcoRI (Gibco-BRL)/MseI (BioLabs), according to the suppliers' recommendations. Samples were heat-treated to inactivate restriction enzyme activity. Next, adaptors (sequences shown in Table 1; synthesized by Invitrogen) were ligated to the DNA restriction fragments by T4 DNA ligase (BioLabs) according to the supplier's recommendations. For rare-cutting enzymes, adaptors were used at a concentration of $5 \mathrm{pmol} \mu \mathrm{l}^{-1}$, and, for frequent-cutting enzymes, at $50 \mathrm{pmol} \mathrm{\mu l}^{-1}$. After completion of ligation, samples were heat-inactivated, diluted 10 -fold in distilled water and refrigerated at $-20{ }^{\circ} \mathrm{C}$ until the start of the PCR. Restriction fragments tagged with specific adaptors were selectively amplified with particular primers (Table 1). PCR was performed in a volume of $20 \mu \mathrm{l}$ in a Biometra thermal cycler. Each amplification reaction mixture contained $5 \mu \mathrm{l} 10$ fold-diluted ligation reaction sample, $12 \mathrm{ng}$ Cy5-labelled primer, $60 \mathrm{ng}$ 


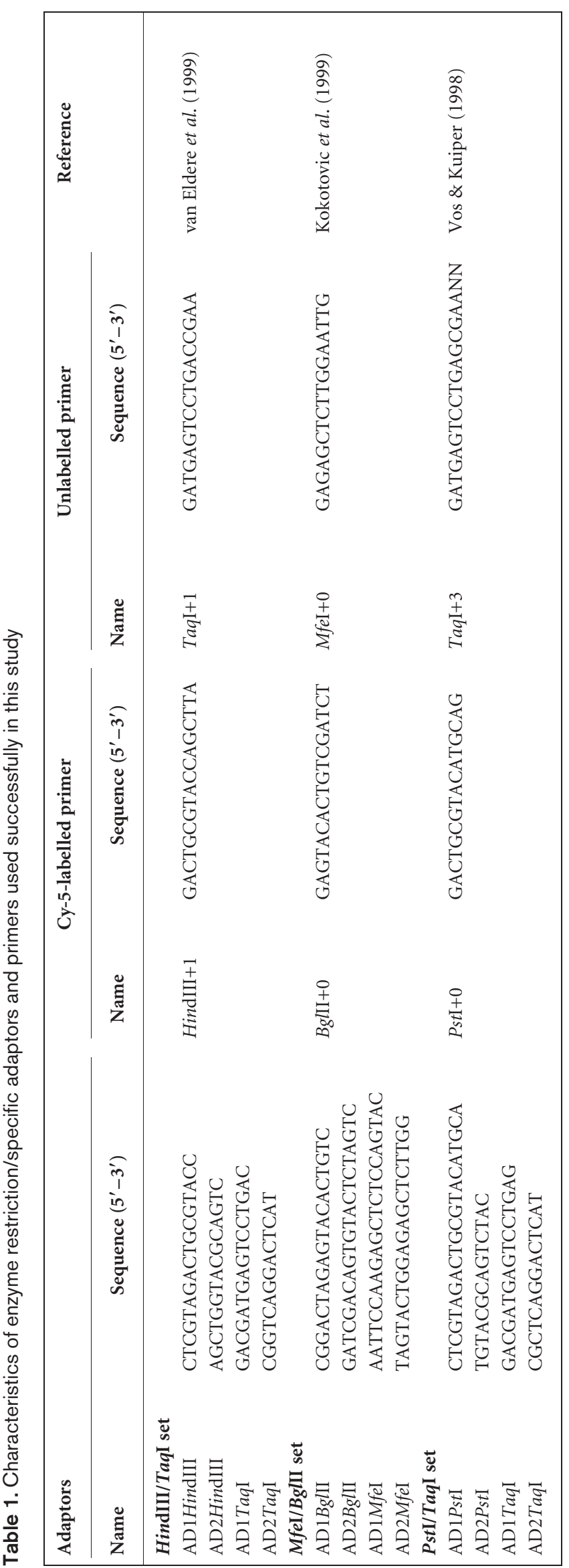

unlabelled primer, $120 \mu \mathrm{M}$ each of dATP, dGTP, dCTP and TTP, $0 \cdot 3 \mathrm{U}$ AccuTaq LA DNA polymerase (Sigma), $3.0 \mathrm{mM} \mathrm{MgCl} 2,50 \mathrm{mM}$ Tris/ $\mathrm{HCl}, 15 \mathrm{mM}$ ammonium sulphate and $0 \cdot 1 \%$ Tween 20 .

After completion of the PCR, $5 \mu$ of each reaction mixture was mixed with $3 \mu \mathrm{l}$ loading dye (Amersham Pharmacia), denatured at $90{ }^{\circ} \mathrm{C}$ for $3 \mathrm{~min}$ and applied to the gel. Selectively amplified fragments were separated through a ReproGel High Resolution (Amersham Pharmacia) in $0.5 \times$ TBE buffer on an ALFexpress DNA sequencer. Separation was done at $1500 \mathrm{~V}, 60 \mathrm{~mA}, 25 \mathrm{~W}$ for $420 \mathrm{~min}$ at $55^{\circ} \mathrm{C}$. In order to evaluate intra- and inter-gel differences and to identity levels, a fluoresceinlabelled molecular size marker in the size range of 50 to $500 \mathrm{bp}$ and an external reference strain were used as external size markers (ALFexpress Sizer 50-500). ALFexpress Sizer 300 added to each sample was used as an internal size marker in each lane. Stored fluorograms were analysed with the Windows version of the GelCompar software version 3.10 (Applied Maths) after conversion to TIF format. Separate electrophoresis gels were normalized according to the internal standards contained in each lane $(300 \mathrm{bp})$. The lane resolution was reduced, excluding the primer front and fragments larger than $500 \mathrm{bp}$. Dendrograms for cluster analysis were based on similarity matrices calculated from Pearson's product-moment correlation coefficient and the UPGMA algorithm (Everitt, 1993). Statistical significance of overall similarities obtained for dendrograms within the seven institutions under study was evaluated by Wilcoxon's test.

\section{RESULTS}

\section{Selection of isolates for examination}

All of the $H$. influenzae isolates $(n=87)$ used in the study were obtained from the nasopharynx of healthy children who were not vaccinated against Hib and who attended six DCCs and three orphanages. The isolates were previously identified by conventional methods including serotyping and this was confirmed by PCR using primers for type b-specific sequences (primers b1 and b2). Additionally, primers $\mathrm{H} 1$ and $\mathrm{H} 2$, directed to bexA, were used to identify encapsulation genes. Thus, among the isolates tested, 9 of $87(10.8 \%)$ and 74 of $87(89.2 \%)$ were respectively identified as Hib and NTHI isolates. An additional four isolates from teachers were classified into the NTHI group. The $H$. influenzae isolates under study are detailed in Table 2.

\section{Analysis of RAPD}

For fingerprinting analysis, six short (10 bp) primers were used for amplification. The H. influenzae strain-specific DNA arrays consisted of approximately $8-15$ bands, with a fragment length distribution in the range of $0 \cdot 1-2 \cdot 0 \mathrm{~kb}$. Of the primers tested, primer VI was found to have greater potential to produce informative DNA profiles. The levels of similarity for patterns obtained for a single strain with primer VI were at least $97 \%$ within the same gel and at least $90 \%$ between gels. Generally, a high level of diversity was found for NTHI isolates; these were clustered into a few clonal groups within one clonal division. The overall genetic similarity of the NTHI isolates within the dendrogram, as defined by Pearson's product-moment correlation coefficient, was $57.3 \%$. At the $70 \%$ level of similarity, five clusters were found, designated A-E (with 24, 21, 6, 13 and 8 isolates, respectively) (Fig. 1). All nine Hib isolates under study were 
Table 2. Characteristics of 87 nasopharyngeal $H$. influenzae isolates investigated in this study

DCC, Day-care centre; O, orphanage; -, not tested; X, non-typable by RAPD; XX, non-typable by AFLP.

\begin{tabular}{|c|c|c|c|c|c|c|c|}
\hline \multirow[t]{2}{*}{ Isolate } & \multirow[t]{2}{*}{ Serotype/genotype } & \multirow{2}{*}{$\begin{array}{l}\text { Age of child } \\
\text { (years) }\end{array}$} & \multirow[t]{2}{*}{ Location } & \multirow[t]{2}{*}{ RAPD type } & \multicolumn{3}{|c|}{ AFLP type } \\
\hline & & & & & HindIII/TaqI & $M f e I / B g l \mathrm{II}$ & PstI/TaqI \\
\hline $1 \mathrm{~W}$ & NTHI & $4 \cdot 5$ & DCC1 & A & CIIc & UB1 & III \\
\hline $2 \mathrm{~W}$ & NTHI & 5 & DCC1 & A & CIIb & UB1 & III \\
\hline $3 \mathrm{~W}$ & NTHI & 5 & DCC1 & A & CIIc & UB3 & III \\
\hline $4 \mathrm{~W}$ & NTHI & 5 & DCC1 & A & CIIc & UB1 & - \\
\hline $6 \mathrm{~W}$ & Hib & $4 \cdot 5$ & DCC1 & $\mathrm{X}$ & $\mathrm{XX}$ & $\mathrm{XX}$ & $\mathrm{XX}$ \\
\hline $7 \mathrm{~W}$ & NTHI & $4 \cdot 5$ & DCC1 & $\mathrm{B}$ & CIIc & UB1 & III \\
\hline $8 \mathrm{~W}$ & NTHI & 4 & DCC1 & A & CIIc & UA2 & III \\
\hline $9 \mathrm{~W}$ & NTHI & 4 & DCC1 & $\mathrm{B}$ & CIIc & UB1 & III \\
\hline $10 \mathrm{~W}$ & NTHI & 4 & DCC1 & $\mathrm{X}$ & $\mathrm{XX}$ & $\mathrm{XX}$ & $\mathrm{XX}$ \\
\hline $11 \mathrm{~W}$ & NTHI & $4 \cdot 5$ & DCC1 & $\mathrm{A}$ & CIIc & UB1 & III \\
\hline $12 \mathrm{~W}$ & $\mathrm{Hib}$ & 4 & DCC1 & $\mathrm{X}$ & $\mathrm{XX}$ & $\mathrm{XX}$ & $\mathrm{XX}$ \\
\hline $13 \mathrm{~W}$ & NTHI & 5 & DCC1 & A & CIIb & UB1 & III \\
\hline $14 \mathrm{~W}$ & NTHI & $3 \cdot 5$ & DCC1 & A & CIa & UB1 & III \\
\hline $15 \mathrm{~W}$ & NTHI & $3 \cdot 5$ & DCC1 & A & CIIc & UB3 & III \\
\hline $17 \mathrm{~W}$ & NTHI & 5 & DCC1 & A & CIIc & UB1 & - \\
\hline $18 \mathrm{~W}$ & NTHI & $3 \cdot 5$ & DCC2 & A & CIIa & UA2 & III \\
\hline $20 \mathrm{~W}$ & NTHI & $3 \cdot 5$ & DCC2 & B & CIIc & UB1 & III \\
\hline $22 \mathrm{~W}$ & NTHI & $2 \cdot 5$ & DCC2 & A & CIIc & UA2 & III \\
\hline $24 \mathrm{~W}$ & NTHI & 4 & DCC2 & - & CIc & - & - \\
\hline $26 \mathrm{~W}$ & NTHI & 3 & DCC2 & A & CIIc & UB1 & III \\
\hline $27 \mathrm{~W}$ & NTHI & 3 & DCC2 & A & CIIa & - & - \\
\hline $30 \mathrm{~W}$ & NTHI & 2 & DCC3 & $\mathrm{D}$ & CIc & UB1 & III \\
\hline $32 \mathrm{~W}$ & NTHI & 2 & DCC3 & A & CIIc & UB1 & III \\
\hline $33 \mathrm{~W}$ & NTHI & 3 & DCC3 & A & CIIc & UB1 & III \\
\hline $34 \mathrm{~W}$ & NTHI & 2 & DCC3 & $\mathrm{C}$ & CIIc & UB3 & III \\
\hline $35 \mathrm{~W}$ & NTHI & 2 & DCC3 & $\mathrm{D}$ & $\mathrm{CIb}$ & UC & III \\
\hline $37 \mathrm{~W}$ & $\mathrm{Hib}$ & 3 & DCC3 & $\mathrm{X}$ & $\mathrm{XX}$ & $\mathrm{XX}$ & $\mathrm{XX}$ \\
\hline $38 \mathrm{~W}$ & NTHI & $2 \cdot 5$ & DCC3 & $\mathrm{C}$ & CIa & UA1 & III \\
\hline $39 \mathrm{~W}$ & Hib & $3 \cdot 5$ & DCC3 & $\mathrm{X}$ & $\mathrm{XX}$ & $\mathrm{XX}$ & XX \\
\hline $40 \mathrm{~W}$ & $\mathrm{Hib}$ & $3 \cdot 5$ & DCC3 & $X$ & $\mathrm{XX}$ & $\mathrm{XX}$ & XX \\
\hline $41 \mathrm{~W}$ & NTHI & 3 & DCC3 & $\mathrm{D}$ & $\mathrm{CIb}$ & UB1 & III \\
\hline $42 \mathrm{~W}$ & NTHI & $3 \cdot 5$ & DCC3 & A & CIIc & UA2 & III \\
\hline $43 \mathrm{~W}$ & $\mathrm{Hib}$ & $2 \cdot 5$ & DCC3 & $X$ & $\mathrm{XX}$ & $\mathrm{XX}$ & XX \\
\hline $44 \mathrm{~W}$ & NTHI & $3 \cdot 5$ & DCC3 & $\mathrm{D}$ & $\mathrm{CIb}$ & UC & III \\
\hline $45 \mathrm{~W}$ & NTHI & 2 & DCC3 & $\mathrm{D}$ & $\mathrm{CIb}$ & - & - \\
\hline $46 \mathrm{~W}$ & NTHI & Teacher & DCC3 & $\mathrm{D}$ & CIId & UB2 & I \\
\hline $47 \mathrm{~W}$ & NTHI & $0 \cdot 58$ & DCC4 & $\mathrm{D}$ & CIId & UB2 & I \\
\hline $48 \mathrm{~W}$ & NTHI & 4 & DCC4 & $\mathrm{D}$ & CIId & UB2 & - \\
\hline $49 \mathrm{~W}$ & NTHI & $4 \cdot 5$ & DCC4 & A & CIIc & - & III \\
\hline $50 \mathrm{~W}$ & NTHI & $3 \cdot 5$ & DCC4 & $\mathrm{C}$ & CIa & UA1 & III \\
\hline $51 \mathrm{~W}$ & NTHI & 4 & DCC4 & $\mathrm{D}$ & CIId & UA3 & I \\
\hline $53 \mathrm{~W}$ & NTHI & $3 \cdot 5$ & DCC4 & - & CIIb & UB2 & I \\
\hline $54 \mathrm{~W}$ & NTHI & 4 & DCC4 & $\mathrm{D}$ & CIId & UB2 & I \\
\hline $55 \mathrm{~W}$ & NTHI & 4 & DCC4 & $\mathrm{D}$ & CIId & UB2 & I \\
\hline $56 \mathrm{~W}$ & NTHI & $0 \cdot 67$ & O7 & B & CIIc & UB3 & III \\
\hline $57 \mathrm{~W}$ & NTHI & $0 \cdot 67$ & O7 & A & CIIc & UA2 & III \\
\hline $58 \mathrm{~W}$ & NTHI & $0 \cdot 5$ & O7 & B & CIIc & UB3 & III \\
\hline $59 \mathrm{~W}$ & NTHI & $0 \cdot 5$ & O7 & B & CIIc & UA2 & III \\
\hline $61 \mathrm{~W}$ & NTHI & 2 & O7 & B & CIIb & UB3 & III \\
\hline $62 \mathrm{~W}$ & NTHI & 2 & O7 & $\mathrm{D}$ & CIIb & UB3 & II \\
\hline $64 \mathrm{~W}$ & NTHI & Teacher & O7 & B & CIIc & UB3 & III \\
\hline
\end{tabular}


Table 2. cont.

\begin{tabular}{|c|c|c|c|c|c|c|c|}
\hline \multirow[t]{2}{*}{ Isolate } & \multirow[t]{2}{*}{ Serotype/genotype } & \multirow{2}{*}{$\begin{array}{l}\text { Age of child } \\
\text { (years) }\end{array}$} & \multirow[t]{2}{*}{ Location } & \multirow[t]{2}{*}{ RAPD type } & \multicolumn{3}{|c|}{ AFLP type } \\
\hline & & & & & HindIII/TaqI & $M f e \mathrm{I} / B g l \mathrm{II}$ & PstI/TaqI \\
\hline $66 \mathrm{~W}$ & NTHI & 1 & O8 & B & CIIb & UB3 & III \\
\hline $67 \mathrm{~W}$ & NTHI & $0 \cdot 25$ & O8 & A & CIIc & UB3 & III \\
\hline $68 \mathrm{~W}$ & NTHI & $0 \cdot 42$ & O8 & B & CIIb & UA2 & III \\
\hline $69 \mathrm{~W}$ & NTHI & $0 \cdot 17$ & O8 & B & $\mathrm{CIIb}$ & UA2 & III \\
\hline $70 \mathrm{~W}$ & NTHI & $1 \cdot 25$ & O8 & $\mathrm{B}$ & CIIc & UA2 & III \\
\hline $71 \mathrm{~W}$ & NTHI & 2 & O8 & A & CIIb & UB3 & III \\
\hline $72 \mathrm{~W}$ & NTHI & 2 & O8 & $\mathrm{B}$ & CIIc & UD3 & III \\
\hline $73 \mathrm{~W}$ & NTHI & $1 \cdot 25$ & O8 & $\mathrm{C}$ & CIIb & UA2 & II \\
\hline $74 \mathrm{~W}$ & NTHI & $1 \cdot 5$ & O8 & B & CIIb & UA2 & III \\
\hline $75 \mathrm{~W}$ & NTHI & $3 \cdot 5$ & O8 & $\mathrm{C}$ & CIIb & UA2 & - \\
\hline $76 \mathrm{~W}$ & NTHI & 2 & O8 & B & CIIb & - & - \\
\hline $77 \mathrm{~W}$ & NTHI & 2 & O8 & B & CIIb & UA2 & III \\
\hline $78 \mathrm{~W}$ & NTHI & $3 \cdot 5$ & O8 & B & CIIc & UA2 & III \\
\hline $81 \mathrm{~W}$ & $\mathrm{Hib}$ & 1 & DCC9 & $\mathrm{X}$ & $\mathrm{XX}$ & $\mathrm{XX}$ & $\mathrm{XX}$ \\
\hline $83 \mathrm{~W}$ & NTHI & $1 \cdot 17$ & DCC9 & A & CIIc & UB3 & III \\
\hline $85 \mathrm{~W}$ & $\mathrm{Hib}$ & 1.5 & DCC9 & $\mathrm{X}$ & $\mathrm{XX}$ & $\mathrm{XX}$ & $\mathrm{XX}$ \\
\hline $86 \mathrm{~W}$ & NTHI & 2 & DCC9 & $\mathrm{D}$ & CIIb & UB3 & III \\
\hline $89 \mathrm{~W}$ & NTHI & 2 & O8 & - & CIIb & UA2 & III \\
\hline $94 \mathrm{~W}$ & NTHI & 2 & DCC10 & B & CIIc & UB3 & III \\
\hline $95 \mathrm{~W}$ & NTHI & 2 & DCC10 & A & CIIc & UB3 & III \\
\hline $97 \mathrm{~W}$ & NTHI & 1 & DCC10 & B & CIIb & UB1 & III \\
\hline $101 \mathrm{~W}$ & NTHI & Teacher & DCC10 & B & CIIc & UB3 & III \\
\hline $102 \mathrm{~W}$ & NTHI & Teacher & DCC10 & - & CIIc & UA2 & I \\
\hline $104 \mathrm{~W}$ & NTHI & 2 & O6 & E & CIId & UB2 & I \\
\hline $105 \mathrm{~W}$ & NTHI & 1 & O6 & E & CIId & UB2 & I \\
\hline $106 \mathrm{~W}$ & NTHI & 2 & O6 & E & CIId & UA3 & I \\
\hline $107 \mathrm{~W}$ & NTHI & 1 & O6 & E & CIId & UA3 & I \\
\hline $108 \mathrm{~W}$ & NTHI & 1 & O6 & B & CIId & UA3 & I \\
\hline $109 \mathrm{~W}$ & NTHI & $0 \cdot 67$ & O6 & E & CIId & UA3 & I \\
\hline $111 \mathrm{~W}$ & NTHI & $0 \cdot 83$ & O6 & $\mathrm{E}$ & CIId & UA3 & I \\
\hline $112 \mathrm{~W}$ & NTHI & $0 \cdot 25$ & O6 & E & CIId & UA3 & - \\
\hline $113 \mathrm{~W}$ & NTHI & $1 \cdot 5$ & O6 & E & CIId & UA3 & I \\
\hline $114 \mathrm{~W}$ & $\mathrm{Hib}$ & $1 \cdot 5$ & O6 & $\mathrm{X}$ & $\mathrm{XX}$ & $\mathrm{XX}$ & $\mathrm{XX}$ \\
\hline $120 \mathrm{~W}$ & NTHI & $2 \cdot 5$ & DCC10 & A & CIIc & UB3 & III \\
\hline $125 \mathrm{~W}$ & NTHI & 4 & DCC10 & - & CIIc & UB3 & III \\
\hline $126 \mathrm{~W}$ & NTHI & $5 \cdot 5$ & DCC10 & - & CIIa & UA2 & III \\
\hline
\end{tabular}

found to represent a single and identical RAPD pattern and were classified by cluster analysis into a single branch of the dendrogram with a $94 \%$ similarity level. No band variation was observed in RAPD band patterns obtained for DNA isolated from seven passages of a single strain or with DNA content in the range 100-500 ng.

\section{Screening of AFLP sets}

Preliminary screening of seven different AFLP schemes tested revealed that one ApaI/TaqI set and the HindIII set were not useful for NTHI typing, as no banding patterns were observed. In the case of the other ApaI/TaqI set and the EcoRI/ MseI set, identical bands patterns were observed for all isolates tested, revealing no potential for discrimination. Of the successful sets, in the PstI/TaqI and MfeI/BglII sets, a larger number of bands (40-60) within profiles was obtained in comparison with the HindIII/TaqI set (16-37 bands). Bands were more equally distributed within profiles for the HindIII/TaqI set.

For the PstI/TaqI and MfeI/BglII sets, in comparison with the HindIII/TaqI scheme, much lower inter- and intra-gel similarity values were found. Generally, overall intra-/intergel similarity levels for the external reference strain were respectively 84/86, 75/81 and 94/96\% for the PstI/TaqI, MfeI/ BglII and HindIII/TaqI sets. In the PstI/TaqI and MfeI/BglII AFLP schemes, lower levels of similarity were associated with difficulties in gel normalization with the internal reference (300 bp marker) included separately in each sample, which 


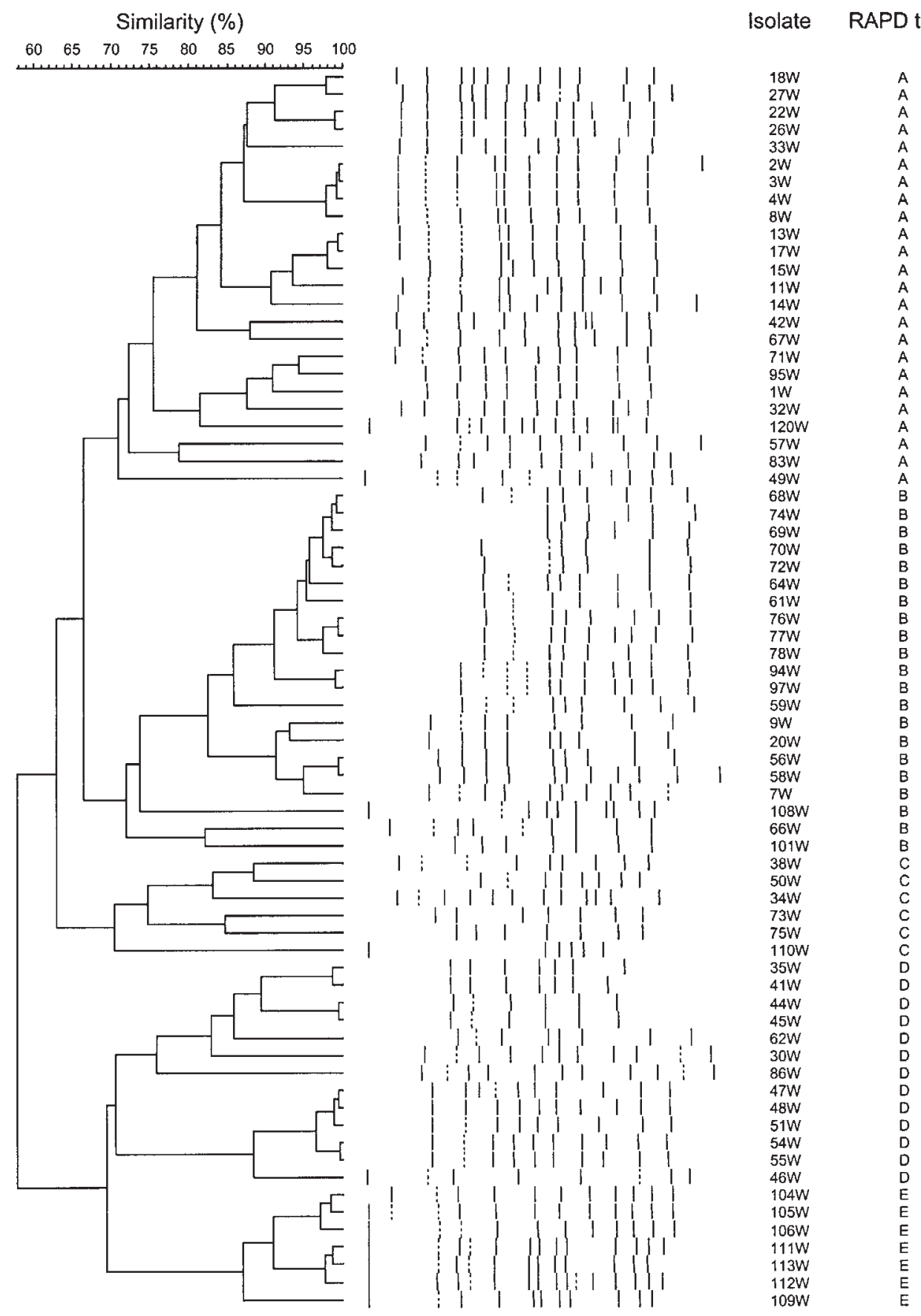

Fig. 1. UPGMA dendrogram of RAPD patterns of NTHI isolates. Characteristics of isolates are listed in Table 2. Levels of linkage are expressed as Pearson's product-moment similarity coefficient.

was often masked with several bands generated in the area close to the internal 300 bp control. Thus, gel normalization in these cases was based exclusively on external reference markers. Overall genetic similarities defined by Pearson's product-moment correlation coefficient for banding patterns of NTHI isolates reached values of $26 \cdot 5,30 \cdot 2$ and $35.4 \%$, respectively, for the PstI/TaqI, MfeI/BglII and HindIII/TaqI AFLP sets. In the case of the MfeI/BglII set, the overall similarity level was $30 \cdot 2 \%$ and three clusters, UA (27 isolates), UB (43 isolates) and UC (two isolates), were identified. Within each of clusters UA and UB, three subclusters, UA1, UA2 and UA3 (with two, 17 and eight isolates, respectively) and UB1, UB2 and UB3 (16, eight and 19 isolates), were defined. In the case of the PstI/TaqI scheme, the overall similarity level was $26.5 \%$ and four clusters, I (15 isolates), II (two isolates), III (46 isolates) and IV (five 
isolates), were differentiated. In the case of the HindIII/TaqI AFLP scheme, the overall similarity was $35.4 \%$ and two main clusters, CI (nine isolates) and CII (68 isolates), were discriminated. Cluster I comprised subclusters CIa, CIb and CIc, respectively containing three, four and two isolates. Within cluster II, three, 17, 33 and 15 isolates made up subclusters IIa, IIb, IIc and IId. High discriminatory power, coupled with the highest identity level among successful AFLP schemes, identified the HindIII/TaqI system as a first method of choice for NTHI strain genotyping (Fig. 2).

DNA isolates obtained from seven subcultures of two different isolates of NTHI repeated over time were used to compare specific pattern reproducibility. The band patterns

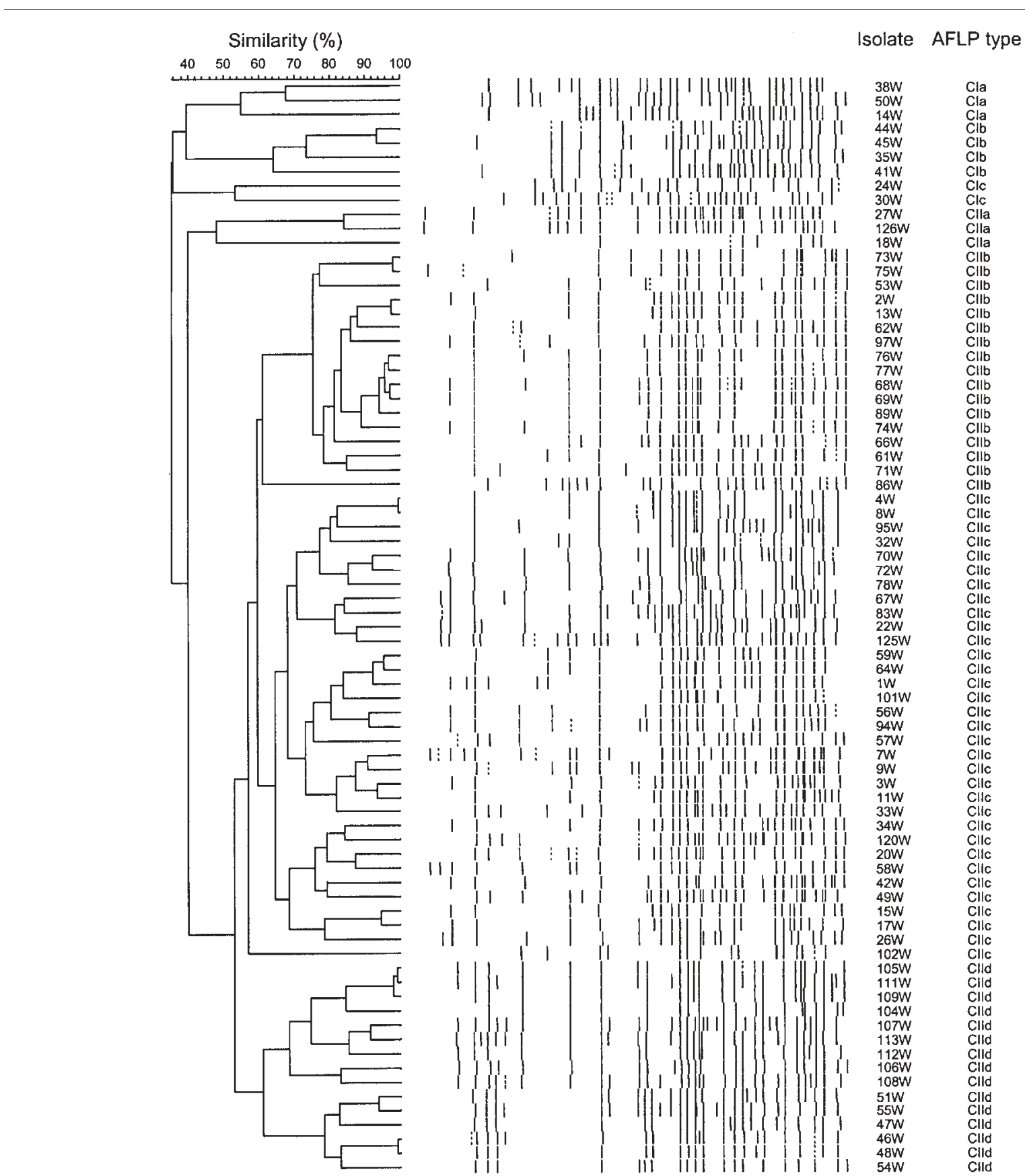

Fig. 2. UPGMA dendrogram of AFLP patterns (HindllI/Taql set) of NTHI isolates. See Fig. 1 for further details. 
did not change after seven passages in any of the isolates tested (data not shown). Similarly, the quantity of DNA in the range 100-500 ng did not induce band variation in the AFLP profile of a single strain. For both the PstI/TaqI and $M f e I / B g l I I$ sets, identical banding profiles were observed for Hib strains, and, for the HindIII/TaqI set, no profiles were observed for Hib strains. The HindIII/TaqI set has been chosen as a first-choice AFLP screening scheme for NTHI typing.

\section{HindIII/Taql AFLP versus RAPD}

The overall genetic similarity of the NTHI isolates genotyped with the HindIII/TaqI AFLP set, as defined by Pearson's product-moment correlation coefficient, was $35 \cdot 4 \%$, which allowed discrimination of patterns with much higher discriminatory power than in the case of RAPD. The dendrogram of RAPD profiles classified all NTHI isolates with $54 \%$ overall similarity, with two main RAPD clusters containing 50 and 21 isolates, respectively subdivided into three and two subclusters (Table 2). In contrast to the overall similarity value of $54 \%$ for RAPD, AFLP with HindIII/TaqI identified six different clusters, containing three, four, two, two, one and 65 isolates. Thus, HindIII/TaqI AFLP presented superior discriminatory power in comparison with the RAPD scheme applied.

\section{AFLP clustering according to institution}

For isolates from eight institutions, dendrograms were constructed for NTHI isolates differentiated with the HindIII/TaqI set. Generally, a much narrower range of highly related overall similarity values was obtained for orphanages (54-67.4\%) (not statistically significantly different, however; $P=0.07)$ in comparison with the overall similarities found within isolates from DCCs $(30-47 \%$ ) (Fig. 3). Overall genetic similarity values for isolates genotyped with the RAPD technique did not reveal any closer relationship between isolates from orphanages (64-70\%) and DCCs (45-88\%) (Fig. 3).

\section{DISCUSSION}

Implementation of vaccination against Hib has generally reduced Hib invasive infections and rates of carriage (Peltola, 2000; Urwin et al., 1996). It is suspected that, in future, NTHI and $H$. influenzae of other capsular types might fill the 'empty' Hib ecological niche in Hib-vaccinated populations, resulting in growing importance of carriage and disease caused by these types (Leaves \& Jordens, 1996). The small but progressive increase in serious disease due to NTHI has prompted researchers to examine the molecular epidemiology of the bacterium (Cerquetti et al., 2000; Falla et al., 1993; Jordens et al., 1993). Studies that have allowed recognition of relationships in the circulating strain population structure were directed towards monitoring their frequency and turnover (Cerquetti et al., 2000; Faden et al., 1995). Several proposed protocols based on different tools, e.g. outermembrane protein typing, MLEE, PFGE, RAPD or multi-

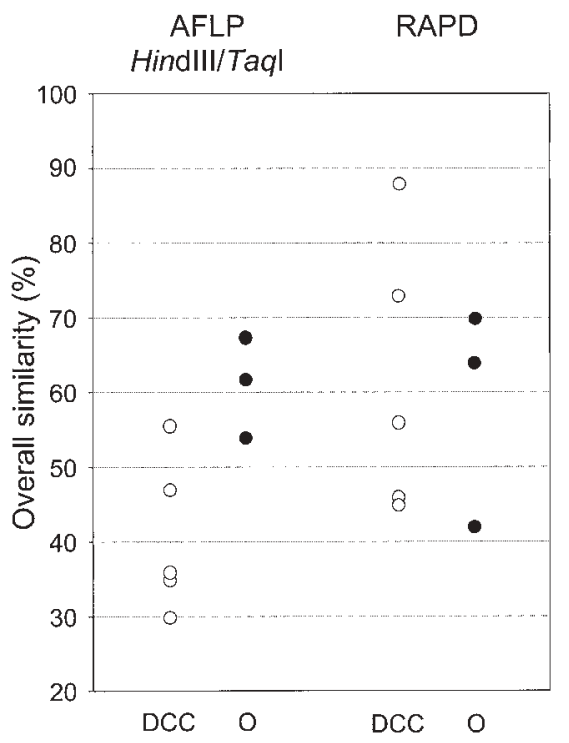

Fig. 3. Distribution of overall similarity values obtained for NTHI isolates within institutions tested. DCC, Day-care centre (open circles); O, orphanage (filled circles).

locus sequence typing, have been used to evaluate NTHI strain relationships (Fuste et al., 1996; Gazagne et al., 1998; Gilsdorf, 1998; Moor et al., 1999; Saito et al., 1999; St Geme et al., 1994; van Belkum et al., 1994, 1997). Of these, some were aimed at finding differences among NTHI strains isolated from patients with persistent infections and from healthy humans (Cerquetti et al., 2000; van Alphen et al., 1991, 1997).

In this study, we describe AFLP as a new tool for generating detailed genotyping data that might be useful for studying relationships between isolates with a discriminatory power much higher than previously described for the RAPD technique. Several AFLP systems, differing in restriction enzyme/ adaptors/primers and conditions and in respect of their usefulness in NTHI epidemiological studies, were tested and compared with the discriminatory capacity of RAPD. The NTHI collection examined comprised $87 \mathrm{H}$. influenzae isolates from the nasopharynx of healthy, unvaccinated 1to 5-year-old children (and their teachers) attending DCCs and orphanages in Poland during January to May 2002. The isolates under study had been characterized by capsular typing with primers designed from the bexA DNA sequence (Falla et al., 1994). Generally, in comparison with Hib, NTHI isolates were found to predominate in $90 \%$ in positive swabs taken from the nasopharynx of individuals tested. Thus, the level of NTHI isolation agrees with studies performed previously, in which NTHI isolates predominated at frequencies of $93-99 \%$ in carriers and $87 \%$ in aboriginal infants (Smith-Vaughan et al., 1998; Trottier et al., 1989).

In order to study the genetic relationships among NTHI isolates collected from different environmental backgrounds, RAPD and AFLP methods were used. As results from the 
RAPD technique have generally been found to be very labile depending on the procedures and reagents used (Heersma et al., 2001; Mori et al., 1999; Olive \& Bean, 1999), a standardized methodology was applied, including commercially available kits for DNA isolation and RAPD amplification to overcome some problems with reproducibility. General approaches were included for reliable and accurate intra- and inter-gel comparison of banding patterns for the two methods (Desai et al., 1998; Janssen, 2001; Savelkoul et al., 1999). Additionally, reproducibility was tested by generation of multiple subcultures on which DNA extraction, RAPD and AFLP procedures (also, on different amounts of DNA) were performed. Intra-/inter-gel reproducibility experiments performed with external references found identity levels for RAPD and for the HindIII/TaqI AFLP set reaching values of $97 / 96$ and $96 / 94 \%$, respectively. Of the seven sets screened, the HindIII/TaqI set was chosen as the first-choice method because it showed the highest levels of identity of the three AFLP schemes that were successful in NTHI genotyping. The overall genetic similarity defined by Pearson's product-moment correlation coefficient was respectively 57.3 and $35.4 \%$ for RAPD and AFLP (HindIII/ TaqI set). Although RAPD can provide data very rapidly, its discriminatory power was much lower in comparison with AFLP.

The non-typable isolates tested appeared to be much more heterogeneous, at a low level of clonality, supporting previously published studies regarding the panmictic population structure (Faden et al., 1995; Falla et al., 1993; Leaves \& Jordens, 1996; Omikunle et al., 2002). Similarly, our data confirmed those published previously on the limited diversity and clonal population structure of Hib-type strains (Fuste et al., 1996; Gazagne et al., 1998; Gilsdorf, 1998; Musser et al., 1988; Saito et al., 1999). All Hib isolates comprising our control group, typed by RAPD and AFLP techniques, were found in a single clade of the dendrograms for both methods. One hypothesis to account for the clonality of Hib, supported by experimental data, is that the capsule acts as a barrier to exogenous DNA (Musser et al., 1988). AFLP patterns were used to investigate whether certain isolates were circulating more frequently within institutions of different environmental backgrounds (DCCs, orphanages) that vary in the intensity of shared living conditions and contact among individuals. The overall similarity values of AFLP dendrograms (HindIII/TaqI scheme) constructed for isolates originating from particular DCCs were lower than those obtained for isolates originating within particular orphanages. No trend was observed in RAPD discriminatory potential. The closer genetic relationship detected among NTHI isolates originating at DCCs, where children are in contact only during the day in the working hours of their parents, was suspected to be much more related to the higher frequency of contact in orphanages, due to permanent, and thus closer, cohabitation in the same environment. Although a high level of diversity has generally been found for NTHI, more frequent transmission of closely related strains among children living together in orphanages can support the idea of an association between transmission rates and environmental factors dependent on contact intensities. It seems that increased transmission rates and repeated passage through human hosts living more closely together might result in more 'clonal' relationships among isolates (Peerbooms et al., 2002). Larger numbers of isolates and institutions need to be compared in order to confirm or reject this hypothesis.

With application of the AFLP technique presented here, understanding of the population structure of NTHI, especially when Hib vaccination is introduced or continued, might provide insights into the emergence of newly acquired clones and/or follow the expansion of clones, to elucidate transmission routes in the community and the reasons for vaccine failure, if the latter occurs. The authors of this study postulate AFLP to be more accurate than the previously described RAPD for definition of bacterial strain differences and for tracking genetic relatedness.

\section{ACKNOWLEDGEMENTS}

This work was supported by grant no. 3 P05D06723 from the State Committee for Scientific Research.

\section{REFERENCES}

Bolduc, G. R., Bouchet, V., Jiang, R.-Z., Geisselsoder, J., TruongBolduc, Q. C., Rice, P. A., Pelton, S. I. \& Goldstein, R. (2000). Variability of outer membrane protein $\mathrm{P} 1$ and its evaluation as a vaccine candidate against experimental otitis media due to nontypeable Haemophilus influenzae: an unambiguous, multifaceted approach. Infect Immun 68, 4505-4517.

Cerquetti, M., Ciofi degli Atti, M. L., Renna, G., Tozzi, A. E., Garlaschi, M. L. \& Mastrantonio, P. (2000). Characterization of non-type b Haemophilus influenzae strains isolated from patients with invasive disease. The HI Study Group. J Clin Microbiol 38, 4649-4652.

Desai, M., Tanna, A., Wall, R., Efstratiou, A., George, R. \& Stanley, J. (1998). Fluorescent amplified-fragment length polymorphism analysis of an outbreak of group A streptococcal invasive disease. JClin Microbiol 36, 3133-3137.

Everitt, B. (1993). Cluster Analysis, 3rd edn. London: Arnold.

Faden, H., Duffy, L., Williams, A., Krystofik, D. A. \& Wolf, J. (1995). Epidemiology of nasopharyngeal colonization with nontypeable Haemophilus influenzae in the first 2 years of life. J Infect Dis 172, 132-135.

Falla, T. J., Dobson, S. R. M., Crook, D. W. M. \& 7 other authors (1993). Population-based study of non-typable Haemophilus influenzae invasive disease in children and neonates. Lancet 341, 851-854.

Falla, T. J., Crook, D. W., Brophy, L. N., Maskell, D., Kroll, J. S. \& Moxon, E. R. (1994). PCR for capsular typing of Haemophilus influenzae. J Clin Microbiol 32, 2382-2386.

Fuste, M. C., Pineda, M. A., Palomar, J., Vinas, M. \& Loren, J. G. (1996). Clonality of multidrug-resistant nontypeable strains of Haemophilus influenzae. J Clin Microbiol 34, 2760-2765.

Gazagne, L., Delmas, C., Bingen, E. \& Dabernat, H. (1998). Molecular epidemiology of ampicillin-resistant non- $\beta$-lactamase-producing Haemophilus influenzae. J Clin Microbiol 36, 3629-3635.

Gilsdorf, J. R. (1998). Antigenic diversity and gene polymorphisms in Haemophilus influenzae. Infect Immun 66, 5053-5059.

Grady, R., Desai, M., O'Neill, G., Cookson, B. \& Stanley, J. (1999). 
Genotyping of epidemic methicillin-resistant Staphylococcus aureus phage type 15 isolates by fluorescent amplified-fragment length polymorphism analysis. J Clin Microbiol 37, 3198-3203.

Hargreaves, R. M., Slack, M. P. E., Howard, A. J., Anderson, E. \& Ramsay, M. E. (1996). Changing patterns of invasive Haemophilus influenzae disease in England and Wales after introduction of the Hib vaccination programme. $B M J 312,160-161$.

Heersma, H. F., Kremer, K., van Soolingen, D. \& Hauman, J. (2001). Setting up intra- and inter-laboratory databases of electrophoretic profiles. In New Approaches for the Generation and Analysis of Microbial Typing Data, pp. 47-77. Edited by L. Dijkshoorn, K. J. Towner \& M. Struelens. Amsterdam: Elsevier.

Huys, G., Coopman, R., Janssen, P. \& Kersters K. (1996). Highresolution genotypic analysis of the genus Aeromonas by AFLP fingerprinting. Int J Syst Bacteriol 46, 572-580.

Janssen, P. J. D. (2001). Selective restriction fragment amplification by AFLP. In New Approaches for the Generation and Analysis of Microbial Typing Data, pp. 177-210. Edited by L. Dijkshoorn, K. J. Towner \& M. Struelens. Amsterdam: Elsevier.

Jordens, J. Z., Leaves, N. I., Anderson, E. C. \& Slack, M. P. E. (1993). Polymerase chain reaction-based strain characterization of noncapsulate Haemophilus influenzae. J Clin Microbiol 31, 2981-2987.

Kokotovic, B., Friis, N. F., Jensen, J. S. \& Ahrens, P. (1999). Amplifiedfragment length polymorphism fingerprinting of Mycoplasma species. J Clin Microbiol 37, 3300-3307.

Leaves, N. I. \& Jordens, J. Z. (1996). Analysis of the prevaccine population of noncapsulate Haemophilus influenzae and identification of a putative epidemic clone. Eur J Clin Microbiol Infect Dis 15, 410-414.

McLauchlin, J., Ripabelli, G., Brett, M. M. \& Threlfall, E. J. (2000). Amplified fragment length polymorphism (AFLP) analysis of Clostridium perfringens for epidemiological typing. Int J Food Microbiol 56, $21-28$.

Meats, E., Feil, E. J., Stringer, S., Cody, A. J., Goldstein, R., Kroll, J. S., Popovic, T. \& Spratt, B. G. (2003). Characterization of encapsulated and noncapsulated Haemophilus influenzae and determination of phylogenetic relationships by multilocus sequence typing. J Clin Microbiol 41, $1623-1636$

Moor, P. E., Collignon, P. C. \& Gilbert, G. L. (1999). Pulsed-field gel electrophoresis used to investigate genetic diversity of Haemophilus influenzae type $\mathrm{b}$ isolates in Australia shows differences between Aboriginal and non-Aboriginal isolates. J Clin Microbiol 37, 1524-1531.

Mori, E., Lio, P., Daly, S., Damiani, G., Perito, B. \& Fani, R. (1999). Molecular nature of RAPD markers from Haemophilus influenzae Rd genome. Res Microbiol 150, 83-93.

Musser, J. M., Kroll, J. S., Moxon, E. R. \& Selander, R. K. (1988). Clonal population structure of encapsulated Haemophilus influenzae. Infect Immun 56, 1837-1845.

Olive, D. M. \& Bean, P. (1999). Principles and applications of methods for DNA-based typing of microbial organisms. J Clin Microbiol 37, $1661-1669$.

Omikunle, A., Takahashi, S., Ogilvie, C. L., Wang, Y., Rodriguez, C. A., St Geme, J. W., III \& Adderson, E. E. (2002). Limited genetic diversity of recent invasive isolates of non-serotype b encapsulated Haemophilus influenzae. J Clin Microbiol 40, 1264-1270.

Peerbooms, P. G. H., Engelen, M. N., Stokman, D. A. J., van Benthem, B. H. B., van Weert, M.-L., Bruisten, S. M., van Belkum, A. \& Coutinho, R. A. (2002). Nasopharyngeal carriage of potential bacterial pathogens related to day care attendance, with special reference to the molecular epidemiology of Haemophilus influenzae. J Clin Microbiol 40, $2832-2836$

Peltola, H. (2000). Worldwide Haemophilus influenzae type b disease at the beginning of the 21st century: global analysis of the disease burden 25 years after the use of the polysaccharide vaccine and a decade after the advent of conjugates. Clin Microbiol Rev 13, 302-317.

Pettigrew, M. M., Foxman, B., Ecevit, Z., Marrs, C. F. \& Gilsdorf, J. (2002). Use of pulsed-field gel electrophoresis, enterobacterial repetitive intergenic consensus typing, and automated ribotyping to assess genomic variability among strains of nontypeable Haemophilus influenzae. J Clin Microbiol 40, 660-662.

Saito, M., Umeda, A. \& Yoshida, S. (1999). Subtyping of Haemophilus influenzae strains by pulsed-field gel electrophoresis. J Clin Microbiol 37, 2142-2147.

Savelkoul, P. H. M., Aarts, H. J. M., de Haas, J., Dijkshoorn, L., Duim, B., Otsen, M., Rademaker, J. L. W., Schouls, L. \& Lenstra, J. A. (1999). Amplified-fragment length polymorphism analysis: the state of an art. J Clin Microbiol 37, 3083-3091.

Smith-Vaughan, H. C., Spiprakash, K. S., Leach, A. J., Mathews, J. D. \& Kemp, D. J. (1998). Low genetic diversity of Haemophilus influenzae type b compared to nonencapsulated $H$. influenzae in a population in which $H$. influenzae is highly endemic. Infect Immun 66, 3403-3409.

Spinola, S. M., Peacock, J., Denny, F. W., Smith, D. L. \& Cannon, J. G. (1986). Epidemiology of colonization by nontypable Haemophilus influenzae in children: a longitudinal study. J Infect Dis 154, 100-109.

St Geme, J. W., III, Takala, A., Esko, E. \& Falkow, S. (1994). Evidence for capsule gene sequences among pharyngeal isolates of nontypeable Haemophilus influenzae. J Infect Dis 169, 337-342.

Trottier, S., Stenberg, K. \& Svanborg-Eden, C. (1989). Turnover of nontypable Haemophilus influenzae in the nasopharynges of healthy children. J Clin Microbiol 27, 2175-2179.

Urwin, G., Krohn, J. A., Deaver-Robinson, K., Wenger, J. D. \& Farley, M. M. (1996). Invasive disease due to Haemophilus influenzae serotype f: clinical and epidemiologic characteristics in the H. influenzae serotype b vaccine era. The Haemophilus influenzae Study Group. Clin Infect Dis 22, 1069-1076.

van Alphen, L., Eijk, P., Geelen-van den Broek, L. \& Dankert, J. (1991). Immunochemical characterization of variable epitopes of outer membrane protein P2 of nontypeable Haemophilus influenzae. Infect Immun 59, 247-252.

van Alphen, L., Caugant, D. A., Duim, B., O’Rourke, M. \& Bowler, L. D. (1997). Differences in genetic diversity of nonencapsulated Haemophilus influenzae from various diseases. Microbiology 143, 1423-1431.

van Belkum, A., Duim, B., Regelink, A., Moller, L., Quint, W. \& van Alphen, L. (1994). Genomic DNA fingerprinting of clinical Haemophilus influenzae isolates by polymerase chain reaction amplification: comparison with major outer-membrane protein and restriction fragment length polymorphism analysis. J Med Microbiol 41, 63-68.

van Belkum, A., Scherer, S., van Leeuwen, W., Willemse, D., van Alphen, L. \& Verbrugh, H. (1997). Variable number of tandem repeats in clinical strains of Haemophilus influenzae. Infect Immun 65, 5017-5027.

van Eldere, J., Janssen, P., Hoefnagels-Schuermans, A., van Lierde, S. \& Peetermans, W. E. (1999). Amplified-fragment length polymorphism analysis versus macro-restriction fragment analysis for molecular typing of Streptococcus pneumoniae isolates. J Clin Microbiol 37, 2053-2057.

Vos, P. \& Kuiper, M. (1998). AFLP analysis. In DNA Markers, Protocols, Applications, and Overviews, pp. 115-131. Edited by G. CaetanoAnolles \& P. M. Gresshoff. Chichester: Wiley. 